\title{
Observations of equatorial plasma bubbles during the geomagnetic storm of October 2016
}

\author{
FuQing Huang 1,2,3, JiuHou Lei ${ }^{1,2,3 *}$, Chao Xiong ${ }^{4}$, JiaHao Zhong ${ }^{5}$, and GuoZhu Li ${ }^{6,7}$ \\ ${ }^{1}$ Chinese Academy of Sciences Key Laboratory of Geospace Environment, School of Earth and Space Sciences, University of Science and Technology of China, \\ Hefei 230026, China; \\ ${ }^{2}$ Mengcheng National Geophysical Observatory, University of Science and Technology of China, Hefei 230026, China; \\ ${ }^{3}$ Chinese Academy of Sciences Center for Excellence in Comparative Planetology, University of Science and Technology of China, Hefei 230026, China; \\ ${ }^{4}$ Electronic Information School, Wuhan University, Wuhan 430072, China; \\ 5Planetary Environmental and Astrobiological Research Laboratory, School of Atmospheric Sciences, Sun Yat-sen University, Zhuhai 519082, China; \\ ${ }^{6}$ Chinese Academy of Sciences Key Laboratory of Earth and Planetary Physics, Institute of Geology and Geophysics, Chinese Academy of Sciences, Beijing \\ 100029, China; \\ ${ }^{7}$ Beijing National Observatory of Space Environment, Institute of Geology and Geophysics, Chinese Academy of Sciences, Beijing 100029, China
}

\section{Key Points:}

- Sunrise EPBs were observed in the geomagnetic storm main phase.

- Post-sunset EPBs were enhanced during the main phase and suppressed throughout the recovery phase.

- Storm-induced electric field variations could be the primary causal factor to produce the EPB variations during the storm.

Citation: Huang, F. Q., Lei, J. H., Xiong, C., Zhong, J. H., and Li, G. Z. (2021). Observations of equatorial plasma bubbles during the geomagnetic storm of October 2016. Earth Planet. Phys., 5(5), 416-426. http://doi.org/10.26464/epp2021043

\begin{abstract}
We investigated the variations of equatorial plasma bubbles (EPBs) in the East-Asian sector during a strong geomagnetic storm in October 2016, based on observations from the Beidou geostationary (GEO) satellites, Swarm satellite and ground-based ionosonde. Significant nighttime depletions of $\mathrm{F}$ region in situ electron density from Swarm and obvious nighttime EPBs in the Beidou GEO observations were observed on 13 October 2016 during the main phase. Moreover, one interesting feature is that the rare and unique sunrise EPBs were triggered on 14 October 2016 in the main phase rather than during the recovery phase as reported by previous studies. In addition, the nighttime EPBs were suppressed during the whole recovery phase, and absent from 14 to 19 October 2016. Meanwhile, the minimum virtual height of $\mathrm{F}$ trace $\left(h^{\prime} \mathrm{F}\right)$ at Sanya $\left(18.3^{\circ} \mathrm{N}, 109.6^{\circ} \mathrm{E}, \mathrm{MLAT} 11.1^{\circ} \mathrm{N}\right)$ displayed obvious changes during these intervals. The $h^{\prime} F$ was enhanced in the main phase and declined during the recovery phase, compared with the values at pre- and post-storm. These results indicate that the enhanced nighttime EPBs and sunrise EPBs during the main phase and the absence nighttime EPBs for many days during the recovery phase could be associated with storm-time electric field changes.
\end{abstract}

Keywords: EPBs; ionospheric irregularities; Beidou GEO TEC; geomagnetic storm; electron density; electric field

\section{Introduction}

It is well known that equatorial plasma bubbles (EPBs) are one of the typical ionospheric irregularities during nighttime at low latitudes and equatorial regions, which can greatly affect the propagation of radio waves and even cause transient communications and navigation outages (Hysell, 2000; Cherniak and Zakharenkova, 2016; Xiong $C$ et al., 2016). Their cause is generally attributed to the Rayleigh-Taylor (R-T) instability mechanism. The initial perturbation seeded at the bottomside of the $\mathrm{F}$ layer under RT instability can grow and drift upward into the higher ionosphere and constitute an EPB structure, manifesting as plasma

Correspondence to: J. H. Lei, leijh@ustc.edu.cn

Received 16 JUN 2021; Accepted 19 JUL 2021.

Accepted article online 16 AUG 2021.

(C)2021 by Earth and Planetary Physics. density depletions or bubbles ranging from a few meters to hundreds of kilometers (Haerendel et al., 1992; Yokoyama et al., 2014). Since the first observation was reported by Booker and Wells (1938), the generation, evolution, distribution, as well as forecasting of EPBs has been a hot topic in space weather research (e.g., Zalesak and Ossakow, 1980; Huang CS and Kelley, 1996; Abdu, 2001; Otsuka et al., 2002; Burke et al., 2004; Huba et al., 2008; Yokoyama et al., 2014; Li GZ et al., 2016, 2018). However, there are still unsolved questions associated with plasma density depletions due to the complicated dynamic and electrodynamic processes in the ionosphere, which can crucially affect EPB occurrence and evolution (Abdu, 2001).

During geomagnetic storms, development and evolution of EPBs show very complex behavior because the ionosphere and thermosphere systems are modulated significantly by energy injec- 
tions from the solar wind and magnetosphere (Gonzalez et al., 1994; Richmond and Lu G, 2000; Lei JH et al., 2008). Many of the previous studies of EPB variations were conducted during geomagnetic storms and exhibited different characteristics. The EPBs are sometimes confined within a narrow longitudinal range and even entirely suppressed during storm time (Carter et al., 2016; Nayak et al., 2017); on the contrary, they can also be significantly enhanced during storms, extending to higher latitudes (Ma GY and Maruyama, 2006; Cherniak and Zakharenkova, 2016) or covering a wide longitudinal range (Tulasi Ram et al., 2008; Li GZ et al., 2010). A statistical analysis from the ROCSAT-1 observaions during 181 geomagnetic storms indicated that the occurrence of EPBs shows typical dependences on local time and storm phases (Wan X et al., 2019). For example, EPB is enhanced shortly at the post-sunset sector during storm onset, but afterwards a long-lasting suppression dominates. In contrast, in the postmidnight sector the occurrence of EPB gradually increases at storm onset and reaches maximum peak at 6-9 hours, and then afterwards gradually decays until 18 hours from the storm onset. Additionally, rare EPBs during the daytime could be successively triggered under geomagnetic disturbance conditions (Huang CS et al., 2013; Tulasi Ram et al., 2015; Jiang CH et al., 2016).

As mentioned above, EPBs have complicated variations during a geomagnetic storm, showing the enhancement, inhibition or seeding of EPBs, etc. They are rarely reported to all occur in the same longitude sector during one geomagnetic storm. In this study, we utilized observations from the Beidou geostationary (GEO) satellites, in situ measurements from the Swarm satellite, and ground-based ionosonde to investigate the responses of EPBs in the East-Asian sector to the October 2016 strong geomagnetic storm. The results show interesting phenomena including the enhanced and suppressed nighttime EPBs as well as unique EPBs triggered at sunrise, which all happened during this storm. Further, the underlying physical mechanisms and processes responsible for the various EPB variations during this storm were explored and discussed.

\section{Geophysical Conditions of the October 2016 Storm and Dataset}

The 13-14 October 2016 geomagnetic storm was a strong geomagnetic storm event during the declining phase of solar cycle 24. Figure 1 shows the relevant solar wind speed, interplanetary magnetic field (IMF) and geomagnetic disturbed conditions during 11-19 October 2016. The storm was initiated with a sudden storm commencement (SSC) at 22:16 universal time (UT) on 12 October when the solar wind speed (Figure 1a) jumped from 340 to $\sim 440 \mathrm{~km} / \mathrm{s}$ at the shock and IMF $B_{z}$ and $B_{y}$ (Figure $1 \mathrm{~b}$ ) underwent obvious disturbances. The Dst index (Figure 1d) also increased at that time and reached $25 \mathrm{nT}$. As the storm progressed and entered the main phase, the IMF $B_{z}$ had a sudden southern excursion from 5 to $-9 \mathrm{nT}$ at 06:12 UT and kept decreasing to $-21 \mathrm{nT}$ until 16:41 UT on 13 October. Meanwhile, the IMF $B_{y}$ with a large negative value of about $-14 \mathrm{nT}$ gradually turned to positive and reached $23 \mathrm{nT}$ at 23:02 UT on 13 October. The corresponding $K p$ index (Figure 1c) exceeded 6 and the Dst dropped to a minimum value of $-104 \mathrm{nT}$ at 23:00 UT on 13 October. Thereafter, the storm entered the recovery phase where IMF $B_{z}$ gradually recovered to a value of $\sim 0 \mathrm{nT}$ with small disturbances and lasted for several days, until 19 October during which the Dst index also showed the corresponding variation to gradual recovery. It should

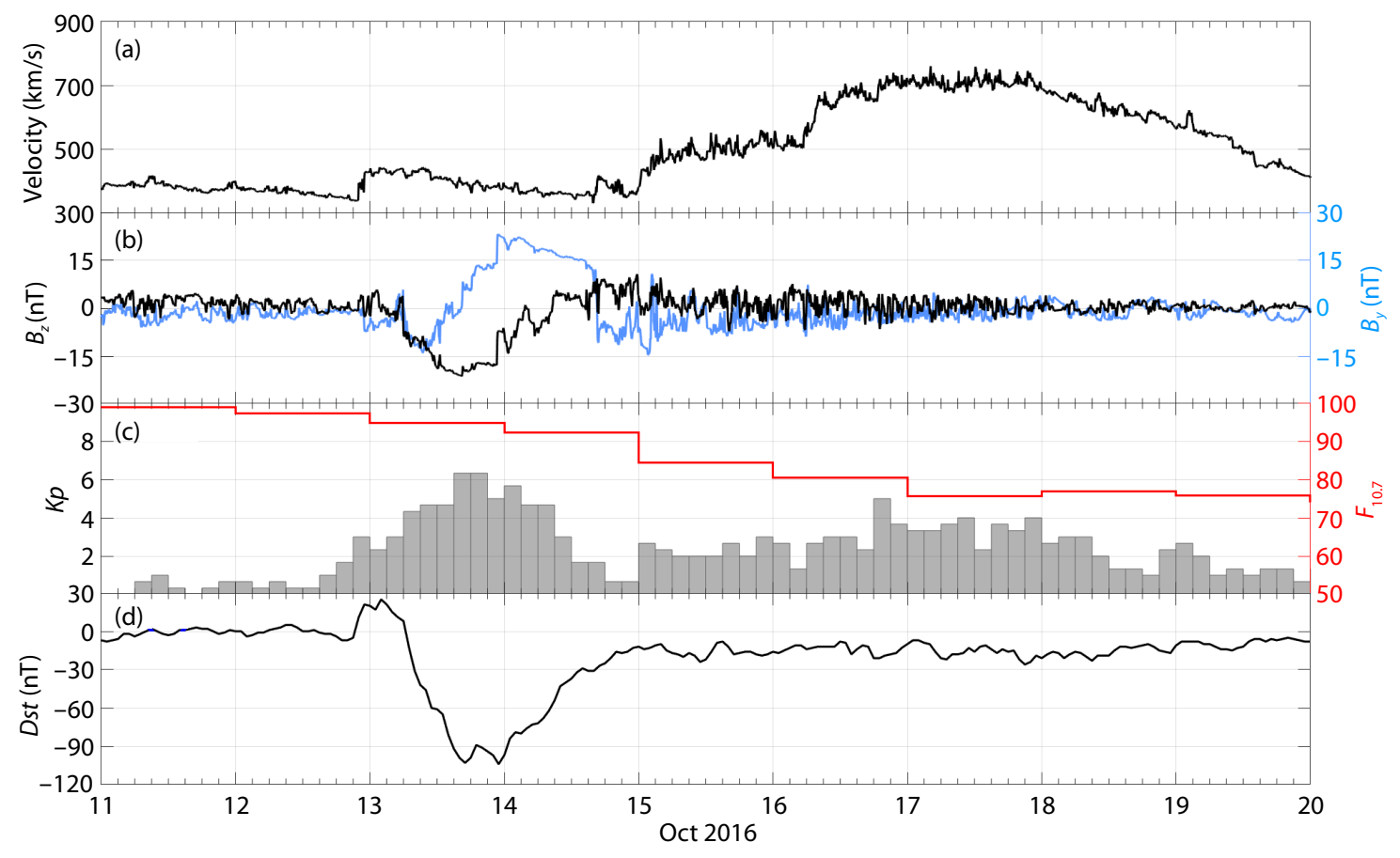

Figure 1. Variations of (a) solar wind speed, (b) interplanetary magnetic field (IMF) $B_{z}$ (black line) and $B_{y}$ (baby blue line) components, and geomagnetic activity indices (c) $K p$ and (d) Dst during 11-19 October 2016. The solar extreme ultraviolet flux proxy $F_{10.7}$ (red line) during this period is also shown in Figure 1c. 
be noted that the solar extreme ultraviolet flux proxy $F_{10.7}$ (red line in Figure 1c) decreased gradually from $~ 99$ on 11 October to 76 on 19 October, and the solar wind speed was significant at more than $700 \mathrm{~km} / \mathrm{s}$ during the recovery phase.

The total electron content (TEC) data from the Beidou GEO satellites was used to investigate the EPB responses to the October 2016 geomagnetic storm. With the advantage that the Beidou GEO TEC provides ionospheric observations along fixed paths since the ionospheric pierce points (IPPs) virtually do not move, it is useful to detect ionospheric variations and structures (e.g., Huang FQ et al., 2017, 2018, 2019, 2021; Lei JH et al., 2018).

Figure 2 shows the location of the stations used for providing the Beidou GEO TEC data in this study. These stations include 9 Global Navigation Satellite System (GNSS) receivers, which can receive signals from multiple satellites including Beidou, GPS and GLONASS, with a time resolution of $30 \mathrm{~s}$. They are approximately located in the longitude sector around $105^{\circ} \mathrm{E}$ at low latitudes and equatorial regions; detailed information for these stations is given in Table 1. There are 5 GEO satellites in the Beidou system that can provide similar TEC observations within several longitude degrees and adjacent latitude for each receiver. In this study, all of them are used to derive the GEO TEC data except when the data were unavailable.

Meanwhile, in situ observations of electron density $\left(N_{e}\right)$ from the Swarm-B satellite were used to investigate the EPB responses in the topside ionosphere during the October 2016 geomagnetic storm. The Swarm mission is a three-satellite constellation of the European Space Agency (ESA) that monitors the Earth's magnetic field and upper atmosphere. During the October 2016 geomagnetic storm, the orbital altitude of Swarm-B was about $512 \mathrm{~km}$, and the equator crossing on the day and night sides were around 08:08 local time (LT) and 20:08 LT, respectively.

In addition, one ground-based ionosonde located at Sanya $\left(18.3^{\circ} \mathrm{N}, 109.6^{\circ} \mathrm{E}\right.$, magnetic latitude (MLAT) $\left.11.1^{\circ} \mathrm{N}\right)$ also shown in Figure 2, was utilized to explore the possible ionospheric electrodynamics process that could affect EPB evolution during the October 2016 geomagnetic storm. Specifically, the variations in the minimum virtual height of $F$ trace $\left(h^{\prime} F\right)$, as it can reflect the changes of F layer bottom height, are analyzed.

\section{Observation Results}

Figure 3 shows the variations of TEC and the rate of TEC change index (ROTI) from Beidou GEO 3 satellite at the equator station ANMG $\left(2.8^{\circ} \mathrm{N}, 101.5^{\circ} \mathrm{E}, \mathrm{MLAT} 6.0^{\circ} \mathrm{S}\right)$, in the East-Asian sector during 12-18 October 2016. The ROTI is an irregularity index proposed by Pi X et al. (1997) to classify ionospheric irregularities. According to Nishioka et al. (2008), in this study we used the ROTI with a 5-min window that exceeds $0.075 \mathrm{TECU} / \mathrm{min}$ for representing irregularities from the TEC data with a time resolution of $30 \mathrm{~s}$. As seen in Figure 3a, Beidou GEO TECs were mostly smooth and showed a general diurnal variation. However, obvious perturbations (irregularities) in the GEO TECs were sometimes observed, such as at 13:00 UT (20:00 LT) on 12 October 2016. These irregularity structures presented obvious depletions or typical EPBs that also corresponded to the large ROTI values. As shown in Figure 3, the EPBs had complex variations during the October 2016 geomagnetic storm. In the main phase, nighttime EPBs were observed at $~ 13: 00$ UT (20:00 LT) on 13 October 2016 similar to the pre-storm period on 12 October 2016. However, the duration of the nighttime EPBs in the main phase was longer than 3 hours. Further, the rare and unique EPBs around sunrise were induced at 23:00 UT (06:00 LT) on 13 October 2016 during the end of the main phase and were not observed on other days. During the recovery phase, an interesting feature was that the EPBs were absent during nighttime, lasting for several days from 14 to 19 October 2016. Usually, nighttime EPBs can be frequently observed in October in the East-Asian sector. In this study, nighttime EPBs were observed a few days before the storm and occurred again after the storm on 20 October 2016 (data not shown).

Next, we examined the EPB variations from 9 Beidou GEO receiver stations at low latitudes and equatorial regions in the East-Asian sector (Figure 4). The evident EPB variations were seen during the October 2016 geomagnetic storm. In the main phase, the rare sunrise EPBs were induced only at 23:00 UT (06:00 LT) on 13 October 2016 over most stations. The long-lasting nighttime EPBs were observed in the main phase as compared to EPBs before the storm on 12 October 2016. During the recovery phase, the night-

Table 1. Coordinate information for the stations that provide Beidou GEO TEC. Geographic and geomagnetic latitudes of Beidou GEO IPP represented by GEO 3 are also provided.

\begin{tabular}{|c|c|c|c|c|c|}
\hline Site & Geographic longitude & Geographic latitude & Geomagnetic latitude & \multicolumn{2}{|c|}{ Latitude of GEO IPP } \\
\hline SHEZ & $111.46^{\circ} \mathrm{E}$ & $26.89^{\circ} \mathrm{N}$ & $20.20^{\circ} \mathrm{N}$ & $24.85^{\circ} \mathrm{N}$ & $18.04^{\circ} \mathrm{N}$ \\
\hline HKWS & $114.34^{\circ} \mathrm{E}$ & $22.43^{\circ} \mathrm{N}$ & $15.47^{\circ} \mathrm{N}$ & $20.80^{\circ} \mathrm{N}$ & $13.74^{\circ} \mathrm{N}$ \\
\hline SYYL & $109.62^{\circ} \mathrm{E}$ & $18.22^{\circ} \mathrm{N}$ & $10.98^{\circ} \mathrm{N}$ & $16.91^{\circ} \mathrm{N}$ & $9.57^{\circ} \mathrm{N}$ \\
\hline EUSM & $100.49^{\circ} \mathrm{E}$ & $5.15^{\circ} \mathrm{N}$ & $3.44^{\circ} \mathrm{S}$ & $4.79^{\circ} \mathrm{N}$ & $3.81^{\circ} \mathrm{S}$ \\
\hline ANMG & $101.51^{\circ} \mathrm{E}$ & $2.78^{\circ} \mathrm{N}$ & $6.00^{\circ} \mathrm{S}$ & $2.59^{\circ} \mathrm{N}$ & $6.18^{\circ} \mathrm{S}$ \\
\hline CIBG & $106.85^{\circ} \mathrm{E}$ & $6.49^{\circ} \mathrm{S}$ & $15.96^{\circ} \mathrm{S}$ & $6.04^{\circ} \mathrm{S}$ & $15.44^{\circ} \mathrm{S}$ \\
\hline COCO & $96.83^{\circ} \mathrm{E}$ & $12.19^{\circ} \mathrm{S}$ & $22.58^{\circ} \mathrm{S}$ & $11.33^{\circ} \mathrm{S}$ & $21.62^{\circ} \mathrm{N}$ \\
\hline
\end{tabular}




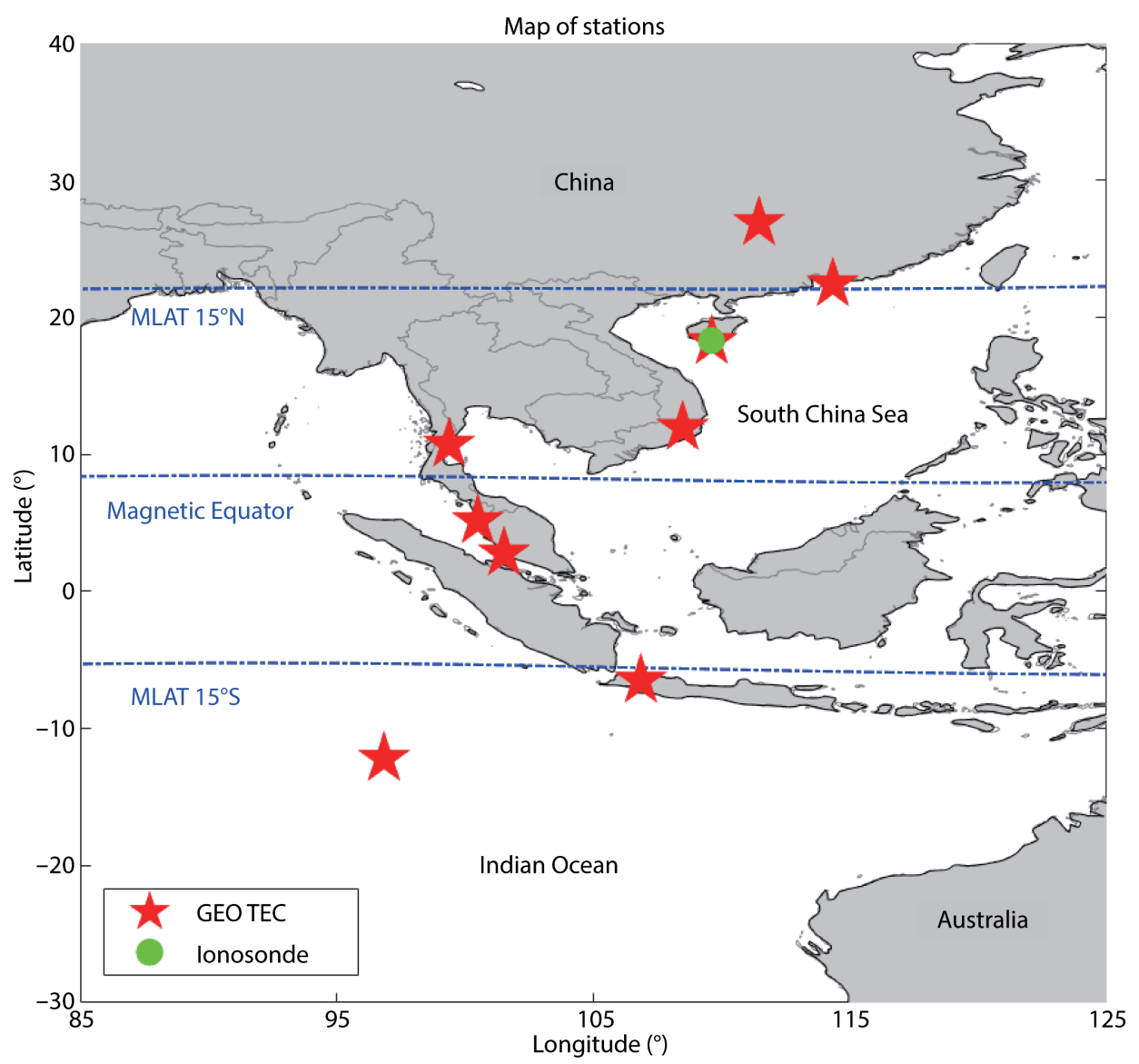

Figure 2. Map of the ionosonde and GNSS receiver stations that provide the Beidou GEO TEC data utilized in this study. The magnetic equator and magnetic latitudes of $\pm 15^{\circ}$ are also shown on this map.

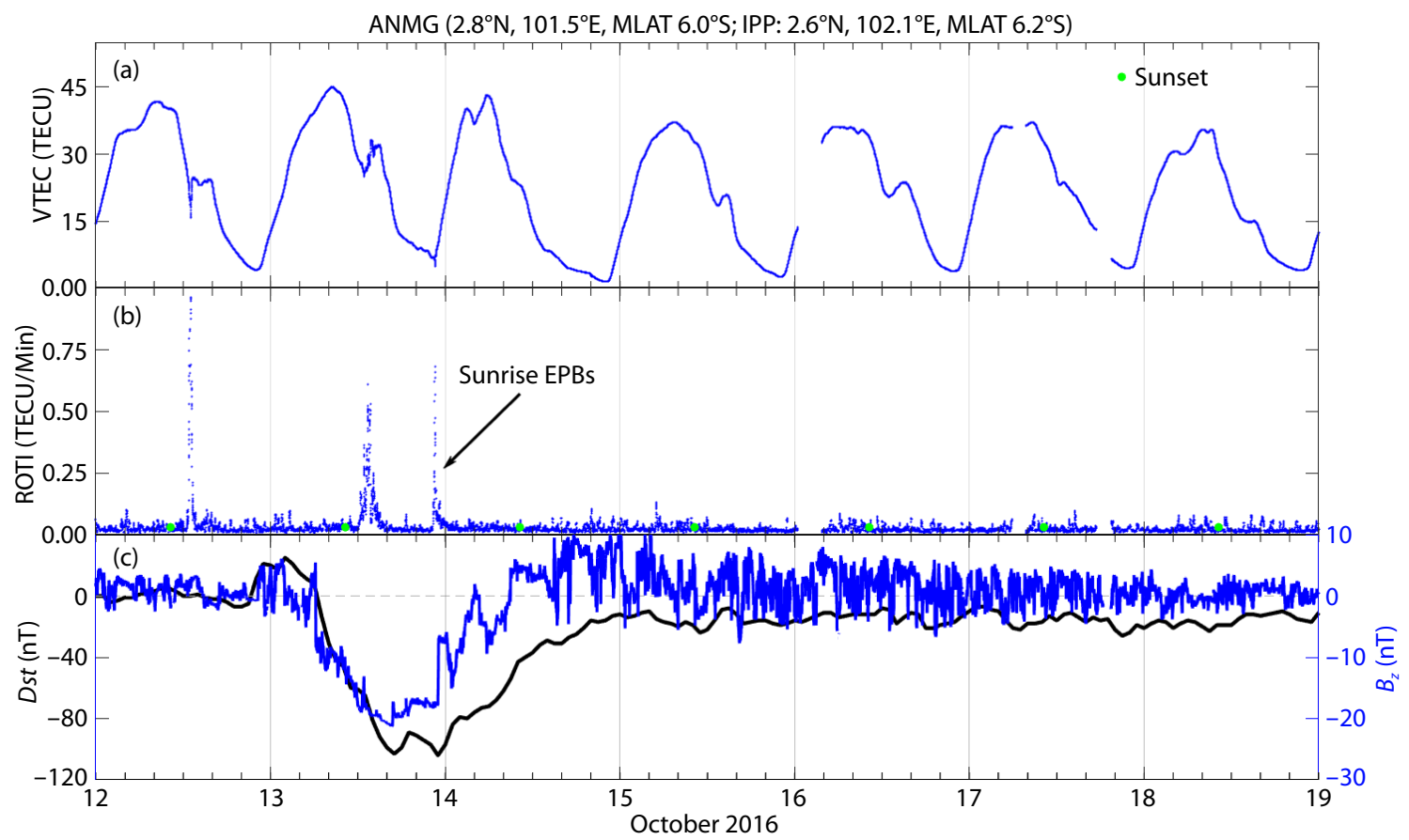

Figure 3. Variations of (a) TEC and (b) ROTI from the Beidou GEO 3 satellite at equator station ANMG during 12-18 October 2016. The sunset at 18:00 LT is marked by the green points. The (c) Dst index (black line) and IMF $B_{z}$ (blue line) are also given for reference. 


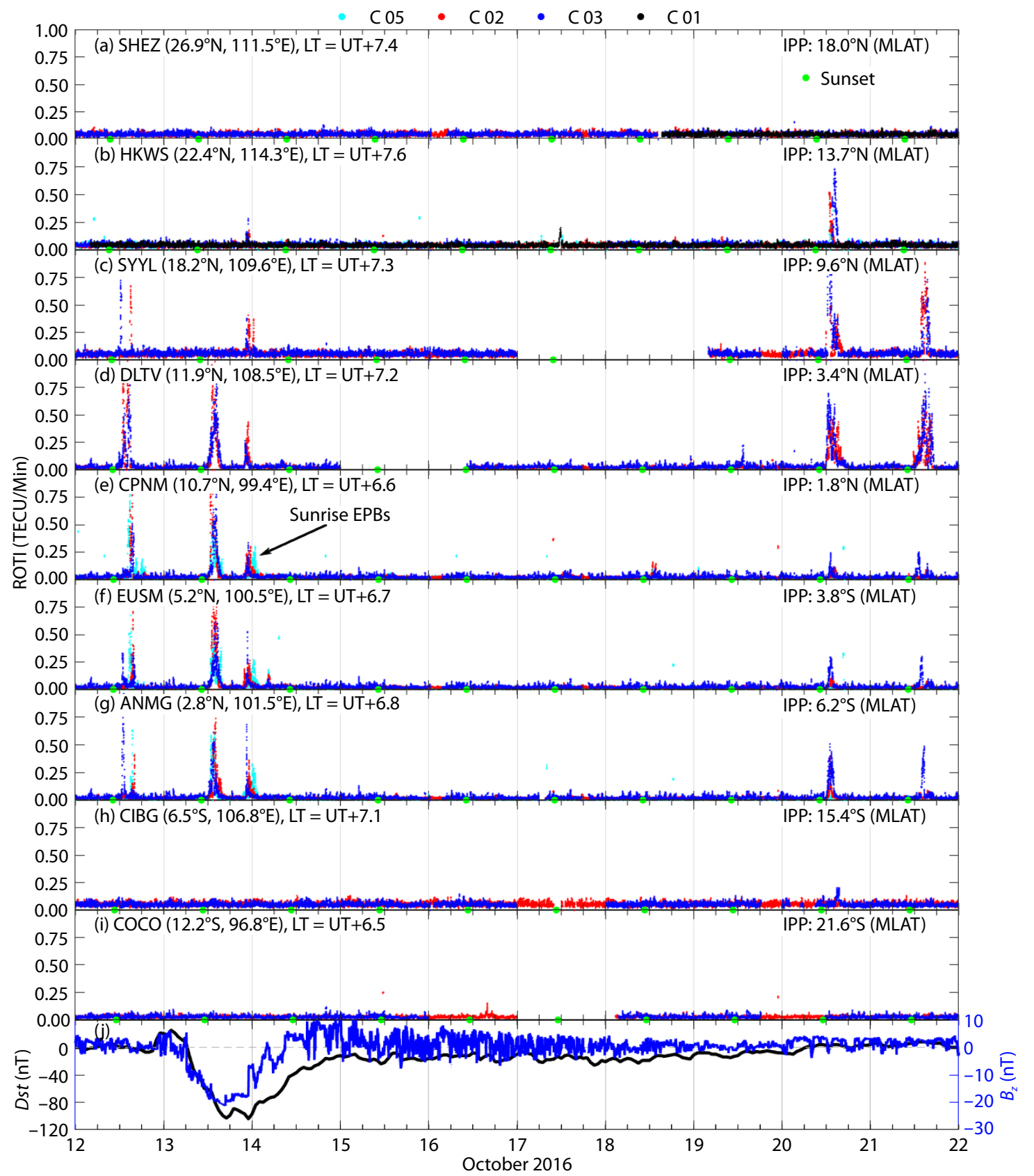

Figure 4. Variations of ROTI from Beidou GEO satellites at low latitudes and equatorial regions in the East-Asian sector from 12 to 21 October 2016. The cyan, red, blue, and black lines represent the ROTI from different Beidou GEO satellites from west to east (GEO 5, GEO 2, GEO 3, and GEO 1). The green points indicate the sunset at 18:00 LT. The Dst index and IMF $B_{z}$ are also plotted in the bottom panel for reference.

time EPBs were totally inhibited at all stations, and were absent for several days from 14 to 19 October 2016. Thereafter, the nighttime EPBs were again observed after the storm between 20 and 21 October 2016 at most of the stations. In addition, it can be seen that the EPBs generally occurred at low magnetic latitudes and magnetic equator regions. They were not observed at higher magnetic latitude stations, such as SHEZ $\left(26.9^{\circ} \mathrm{N}, 111.5^{\circ} \mathrm{E}, \mathrm{MLAT}\right.$ $\left.20.2^{\circ} \mathrm{N}\right)$ and $\operatorname{COCO}\left(12.2^{\circ} \mathrm{S}, 96.8^{\circ} \mathrm{E}, \mathrm{MLAT} 22.6^{\circ} \mathrm{S}\right)$.

In addition, we compared observations at the topside ionosphere from the Swarm-B satellite in order to further explore the EPB responses to this storm. Figures 5 and 6 show the variations of $N_{e}$ during daytime at 08:08 LT and nighttime at 20:08 LT from 12 to
21 October 2016, respectively. The results from the Swarm-B satellite observations were generally consistent with that from ground-based Beidou GEO observations. Significant depletions in $N_{\mathrm{e}}$ at 08:08 LT (black arrows in Figure 5a) with rare typical sunrise EPBs were only observed around the magnetic latitudes $5^{\circ}-10^{\circ}$ in both hemispheres on 14 October 2016 during the main phase. During nighttime, EPBs were also observed around low magnetic latitudes on 13 October in the main phase (black arrows in Figure 6a), and they were suppressed and disappeared for several days during the recovery phase. However, it should be noted that the $N_{\mathrm{e}}$ depletions were stronger by about of $0.5 \times 10^{5} \mathrm{el} / \mathrm{cm}^{3}$ in the main phase, whereas no obvious depletions in $N_{\mathrm{e}}$ were ob- 

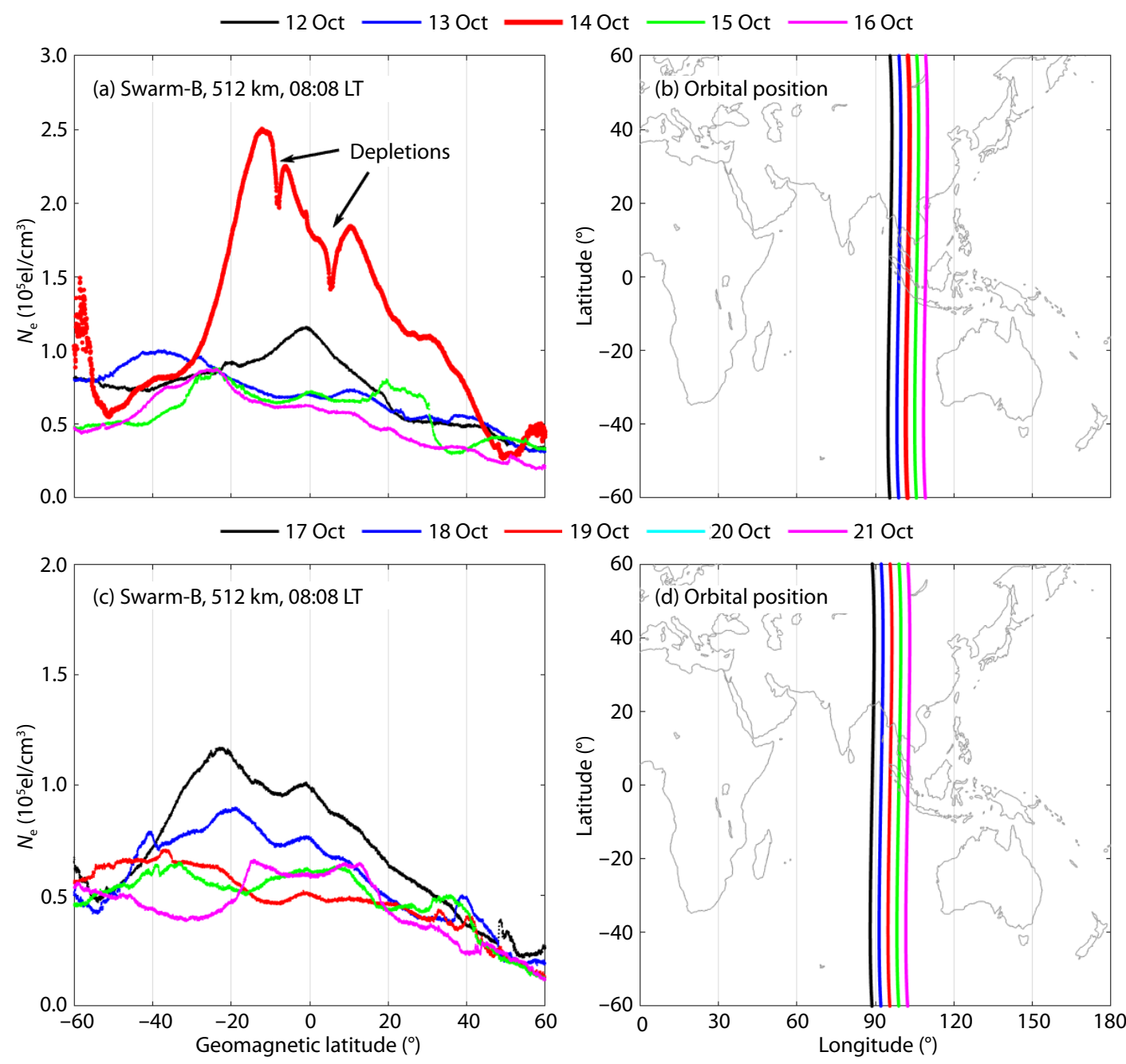

Figure 5. Comparison of the geomagnetic latitudinal profiles of (a and c) electron density during daytime at 08:08 LT at a similar longitude and for the corresponding orbital passes (b and d) from 12 to 21 October 2016 from Swarm-B.

served at pre-storm on 12 October 2016 or at post-storm on 20 and 21 October 2016. Nevetheless, the nighttime EPBs were evident from the Beidou GEO observations during those periods. In addition, there were depletions with amplitude about of $0.2 \times 10^{5} \mathrm{el} / \mathrm{cm}^{3}$ in $N_{\mathrm{e}}$ (green line in Figure 6c) around the magnetic equator on 18 October 2016, which could be the manifestation of nighttime EPBs. However, the nighttime EPBs were not observed in Beidou GEO TEC on that day.

\section{Discussion}

The above results show that the responses of EPBs to the October 2016 geomagnetic storm had various interesting and unique characteristics. The sunrise EPBs were previously reported to occur mainly during the recovery phase (e.g., Huang CS et al., 2013; Tulasi Ram et al., 2015; Jiang CH et al., 2016; Sripathi et al., 2018; Luo WH et al., 2020; Wu K et al., 2020). However, in this event the sunrise EPBs were induced during the end of the main phase. As one of the sources, the sunrise EPBs could be the remnant of the previous nighttime EPBs (e.g., Fukao et al., 2003; Huang CS et al., 2013). However, the previous nighttime EPBs at 13:00 UT (20:00 LT) on 13 October were separated from the later sunrise EPBs
(Figures 3 and 4). In addition, we examined the $N_{\mathrm{e}}$ at 04:04 LT on 14 October from Swarm-A in the East-Asian sector (data not shown); there were no obvious irregularities at low magnetic latitudes, suggesting that the sunrise EPBs were freshly generated during this storm.

The EPBs at low latitudes are generally considered to be generated by the R-T instability mechanism (Kelley, 2009; Makela and Otsuka, 2012), which is controlled and affected by multiple factors including zonal electric fields, background ionospheric density, meridional neutral wind, etc. (Abdu, 2001). During the geomagnetic storm, the ionospheric electric fields can be significantly changed and modulated by the prompt penetration electric field (PPEF) and disturbance dynamo electric field (DDEF) (Blanc and Richmond, 1980; Fejer and Scherliess, 1997). Previous studies reported that the sunrise EPBs during the recovery phase could be associated with the DDEF through its effects upon the R-T instability mechanism (e.g., Huang CS et al., 2013; Tulasi Ram et al., 2015; Jiang CH et al., 2016; Sripathi et al., 2018; Luo WH et al., 2020; Wu K et al., 2020). Here, the sunrise EPBs occurred at the end of the main phase when the IMF $B_{z}$ remained southward. The PPEF can be triggered at the onset of southward IMF $B_{z}$ excursions and lasts 

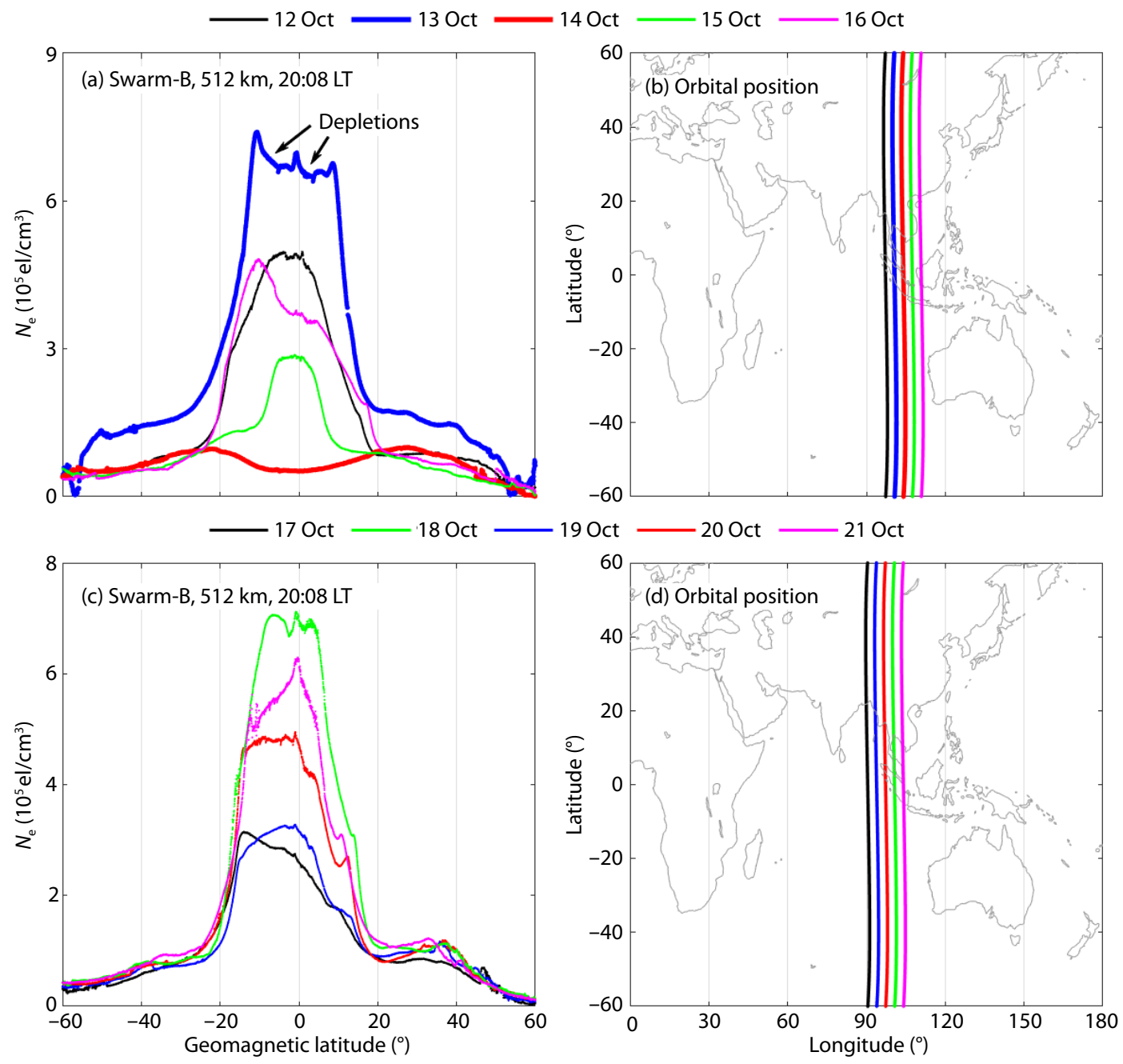

Figure 6. Same as Figure 5, but during nighttime at 20:08 LT.

tens of minutes to several hours during the main phase (Blanc and Richmond, 1980); it is usually eastward and has larger values around dawn (Fejer and Scherliess, 1997). The larger eastward PPEF can produce the stronger upward $E \times B$ draft that could push up the ionospheric height, and resulting in a higher growth rate of R-T instability stimulating EPB development. As shown in Figure 7 , the $h^{\prime} \mathrm{F}$ at Sanya $\left(18.3^{\circ} \mathrm{N}, 109.6^{\circ} \mathrm{E}, \mathrm{MLAT} 11.1^{\circ} \mathrm{N}\right)$ around dawn on 13 October (blue line) during the main phase was 50-100 km higher than on other days. This indicates that the bottom $\mathrm{F}$ layer was pushed to higher altitudes that could easily induce the sunrise EPBs, which could be attributed to the PPEF in this study.

The DDEF could also develop several hours after the onset of PPEF and lasts several days during the recovery phase (Blanc and Richmond, 1980). From post-minight to early morning hours, the DDEF is also eastward and has larger values (Fejer et al., 2008; Xiong $C$ et al., 2015) and could have already developed when the sunrise EPBs occurred. The eastward DDEF can also produce upward drifts to increase the ionospheric height around dawn (Fejer and Scherliess, 1997), which could contribute to the generation of sunrise EPBs. Additionally, the equatorward meridional wind could also affect the EPBs that were triggered around sunrise. It would be enhanced during nighttime due to the strong energy injection at high latitudes in the initial and main phases of the geomagnetic storm (Anderson, 1976; Fejer et al., 2002; Lin et al., 2005). More plasma can be dragged along magnetic field lines from the off-equatorial region towards the higher altitudes at the equatorial region due to stronger equatorial eastward electric fields, combined with the enhanced equatorward meridional wind, causing higher background electron density (Lin $\mathrm{CH}$ et al., 2005). There were large TECs after midnight from 9 GEO receiver stations (data not shown) and high $N_{\mathrm{e}}$ at 08:08 LT from Swarm-B around the magnetic equator. However, the respective contribution from the PPEF and DDEF as well as the equatorward meridional wind to the occurrence of the sunrise EPBs is unclear, due to lack of corresponding observations. Further investigation is needed to address this issue in the future.

In addition, our study revealed that nighttime EPBs were enhanced in the main phase, while eastward PPEF with the largest values around dusk could be developed at pre-midnight (Fejer et al., 2008). PPEF can push up the ionosphere and promote nighttime EPB development into higher altitudes. Thus, nighttime EPBs generated at the bottomside of the $F$ layer could easily grow up into the topside ionosphere due to eastward PPEF effects. Here, 

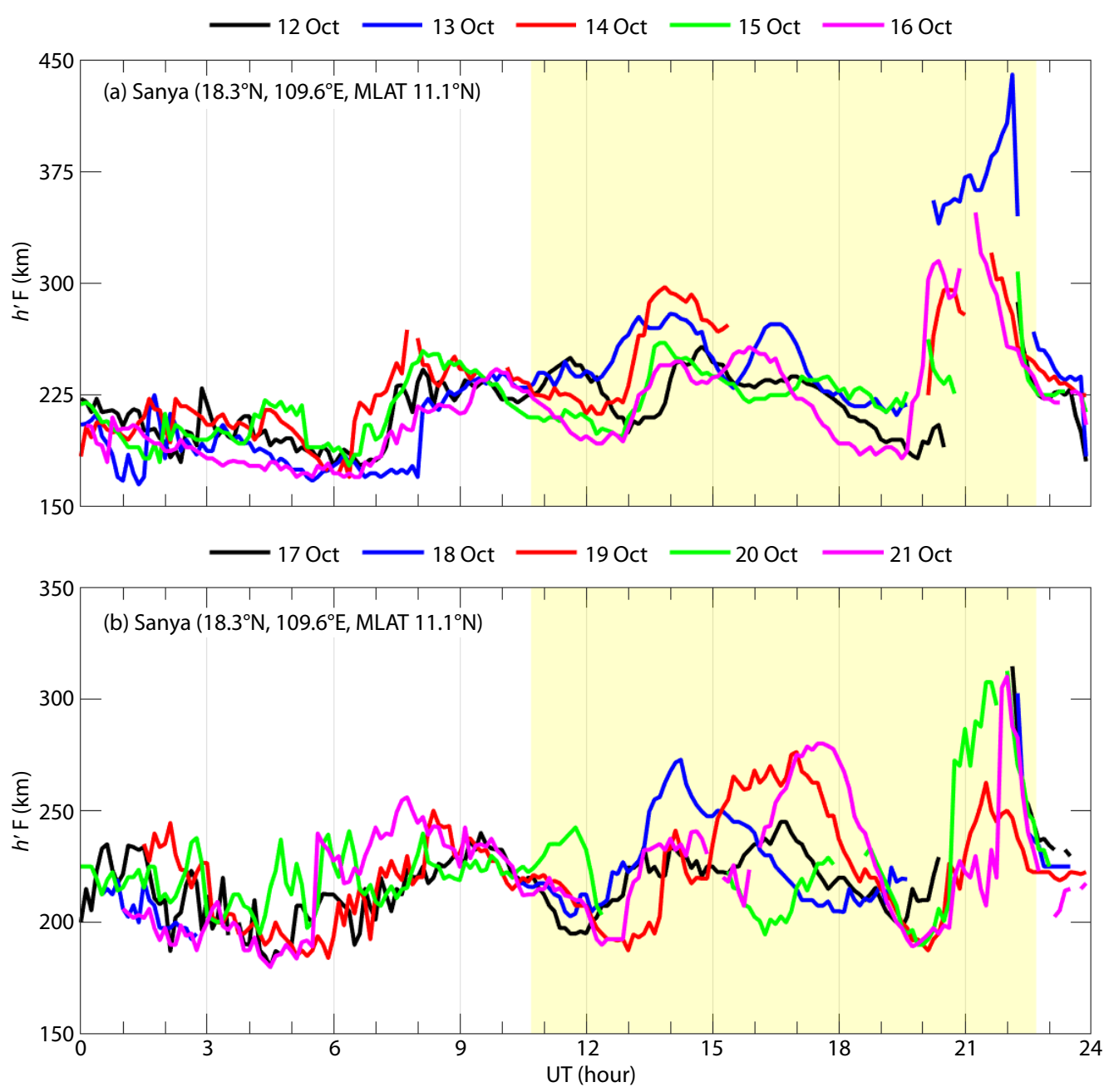

Figure 7. Temporal variations of $h^{\prime}$ F provided by the ionosonde at Sanya $\left(18.3^{\circ} \mathrm{N}, 109.6^{\circ} \mathrm{E}, \mathrm{MLAT} 11.1^{\circ} \mathrm{N}\right)$ during $12-21$ October 2016. The yellow shading denotes nighttime.

we observed stronger depletions in $N_{\mathrm{e}}$ at 20:08 LT in the main phase than other periods (Figure 6). In addition, there was the higher $h^{\prime} \mathrm{F}$ at Sanya during 12:00-15:00 UT (19:18-21:18 LT) when the enhanced nighttime EPBs occurred on 13 October in the main phase, which was $\sim 100 \mathrm{~km}$ higher than at pre-storm on 12 October. This could also explain why the duration of nighttime EPBs in the main phase was longer than at pre-storm.

There were suppressed nighttime EPBs observed during this geomagnetic storm, absent throughout the recovery phase. It is wellknown that pre-midnight EPBs can occur easily when the bottomside of the ionospheric $\mathrm{F}$ layer remains at higher altitudes around sunset, which can be significantly affected by equatorial zonal electric fields such as the pre-reversal eastward electric field enhancement (PRE). The effects of DDEF can become dominant in the recovery phase and exist persistently during this period. As suggested by Abdu (1997), both the zonal and meridional disturbance winds seem to inhibit EPB development through affecting DDEF during the storm. The DDEF is westward and has larger values around sunset (Fejer et al., 2008) that would push the ionospheric plasma to lower altitudes. As seen in Figure 7, the $h^{\prime} \mathrm{F}$ at Sanya during 10:45-12:15 UT (18:03-19:33 LT) in the recovery phase was $\sim 30-50 \mathrm{~km}$ lower than before (12 October) and after (20 October) the storm. The lower ionospheric altitudes associated with the DDEF during the recovery phase were not conducive to the generation of pre-midnight EPBs. This could explain why the pre-midnight EPBs did not happen during the recovery phase as compared with at pre- and post-storm. The development of EPBs also depends on perturbation seeding (i.e., lower atmospheric activities, gravity waves). In addition, the effects from the gravity wave vertical wind component and the background vertical wind can suppress the development of EPBs (Krall et al., 2013). Moreover, the atmospheric composition (i.e., $\mathrm{O}, \mathrm{N}_{2}$ ) and ionospheric conductivity can change significantly during a geomagnetic storm, which can also modulate the growth rate of R-T instability. Unfortunately, the observations of atmospheric composition, ionospheric conductivity and gravity waves were unavailable in this study. These aspects require further investigation.

It should be noted that there also existed differences between ground-based GEO TEC and in situ $N_{\mathrm{e}}$ observations. The nighttime EPBs were prominent from the Beidou GEO observations whether during the storm or not (Figures 3-4), although their duration in the main phase was longer than that at pre-storm, where- 
as the depletions in $N_{\mathrm{e}}$ were strongest in the main phase than other periods (Figure 6). As analyzed above, the nighttime EPBs could develop into higher altitudes in the main phase due to the eastward PPEF effects, which may be ineffective during quiescent times. In addition, it can be found that the observed sunrise EPBs from Swarm-B were at 08:08 LT (Figure 5) while they had already disappeared in the Beidou GEO TECs (Figure 4). The depletions after sunrise could last for a longer time at higher altitudes than at lower altitudes where the photoionization rate is stronger, which can easily produce new plasma to fill the daytime bubbles (Huang CS et al., 2013). In addition, weak nighttime EPBs in $N_{\mathrm{e}}$ around the geomagnetic equator were observed on 18 October 2016, whereas they were not observed in Beidou GEO TECs. The absence of EPB in Beidou GEO TEC at equatorial latitude could also be due to the fact that the satellite-receiver links did not pass through the topside ionospheric depletion structures.

Finally, it is worth noting that the enhanced and suppressed nighttime EPBs and the EPBs triggered at sunrise were reported to occur in the East-Asian sector during one geomagnetic storm. As discussed above, these distinctive EPB variations could be attributed to storm-induced electric field variations including the PPEF, DDEF or both of them. Our results could improve our understanding of EPB generation and evolution during geomagnetically disturbed periods.

\section{Conclusion}

This study investigated the EPB responses to a strong geomagnetic storm of October 2016 in the East-Asian sector by using the ground-based Beidou GEO TEC and ionosonde data as well as space-borne observations from the Swarm satellite. Different EPB variations were observed during this geomagnetic storm. The EPBs were enhanced in the main phase, showing great nighttime $N_{\mathrm{e}}$ depletions in the topside ionosphere observed on 13 October 2016. Furthermore, the sunrise EPBs as rare and unique irregularity structures were triggered on 14 October 2016 in the main phase. The higher $h^{\prime} \mathrm{F}$ at Sanya was observed during the main phase when the strong nighttime EPBs and sunrise EPBs occurred. During the recovery phase from 14 to 19 October 2016, the EPBs were absent. The $h^{\prime} \mathrm{F}$ at Sanya decreased around sunset during this period as compared with the EPBs before and after the storm. This suggests that the storm-induced electric field variations including effects from PPEF and DDEF could be the major contribution to the enhanced nighttime EPBs and the generation of rare sunrise EPBs in the main phase, as well as the absence of EPBs during the recovery phase.

\section{Acknowledgement}

This work was supported by the National Natural Science Foundation of China (41831070, 41974181), the Project of Stable Support for Youth Team in Basic Research Field, CAS (YSBR-018), the B-type Strategic Priority Program of the Chinese Academy of Sciences (XDB41000000), and the Open Research Project of Large Research Infrastructures of CAS-"Study on the interaction between low/mid-latitude atmosphere and ionosphere based on the Chinese Meridian Project". F. Q. Huang was supported by the National Natural Science Foundation of China (42004136), the China
Postdoctoral Science Foundation (2020T130628 and 2019M662170), the Fundamental Research Funds for the Central Universities (WK2080000130) and the Joint Open Fund of Mengcheng National Geophysical Observatory (No. MENGO202010). J. H. Zhong was supported by the National Natural Science Foundation of China (41804150) and the Guangdong Basic and Applied Basic Research Foundation (2021A1515011216). We acknowledge OMNIWeb (https://omniweb.gsfc.nasa.gov/) for Kp, $V_{s w}, B_{z}, B_{y}$, Dst and $F_{10.7}$; Beidou GEO TEC data are provided by the University of Science and Technology of China, the Data Center for Geophysics, National Earth System Science Data Sharing Infrastructure at BNOSE, IGGCAS (http://wdc.geophys.ac.cn/), and NASA CDDIS (https://cddis.gsfc.nasa.gov/); the ionosonde data at Sanya are provided by the University of Massachusetts Lowell DIDBase (http://umlcar.uml.edu/DIDBase/); the Swarm data are obtained from the ESA Earth Online service (http://earth.esa. int/swarm/). We thank the data resources from the National Space Science Data Center, National Science \& Technology Infrastructure of China (http://www.nssdc.ac.cn/eng/).

\section{References}

Abdu, M. A. (1997). Major phenomena of the equatorial ionospherethermosphere system under disturbed conditions. J. Atmos. Sol.-Terr. Phys., 59(13), 1505-1519. https://doi.org/10.1016/S1364-6826(96)00152-6

Abdu, M. A. (2001). Outstanding problems in the equatorial ionospherethermosphere electrodynamics relevant to spread F. J. Atmos. Sol.-Terr. Phys., 63(9), 869-884. https://doi.org/10.1016/S1364-6826(00)00201-7

Anderson, D. N. (1976). Modeling the midlatitude F-region ionospheric storm using east-west drift and a meridional wind. Planet. Space Sci., 24(1), 69-77. https://doi.org/10.1016/0032-0633(76)90063-5

Blanc, M., and Richmond, A. D. (1980). The ionospheric disturbance dynamo. J. Geophys. Res.: Space Phys., 85(A4), 1669-1686. https://doi.org/10.1029/JA085iA04p01669

Booker, H. G., and Wells, H. W. (1938). Scattering of radio waves by the F-region of the ionosphere. Terr. Magn. Atmos. Electr., 43(3), 249-256. https://doi.org/10.1029/TE043i003p00249

Burke, W. J., Gentile, L. C., Huang, C. Y., Valladares, C. E., and Su, S. Y. (2004). Longitudinal variability of equatorial plasma bubbles observed by DMSP and ROCSAT-1. J. Geophys. Res.: Space Phys., 109(A12), A12301. https://doi.org/10.1029/2004JA010583

Carter, B. A., Yizengaw, E., Pradipta, R., Retterer, J. M., Groves, K., Valladares, C., Caton, R., Bridgwood, C., Norman, R., and Zhang, K. (2016). Global equatorial plasma bubble occurrence during the 2015 St. Patrick's Day storm. J. Geophys. Res.: Space Phys., 121(1), 894-905. https://doi.org/10.1002/2015JA022194

Cherniak, I., and Zakharenkova, I. (2016). First observations of super plasma bubbles in Europe. Geophys. Res. Lett., 43(21), 11137-11145. https://doi.org/10.1002/2016GL071421

Fejer, B. G., and Scherliess, L. (1997). Empirical models of storm time equatorial zonal electric fields. J. Geophys. Res.: Space Phys., 102(A11), 24047-24056. https://doi.org/10.1029/97JA02164

Fejer, B. G., Emmert, J. T., and Sipler, D. P. (2002). Climatology and storm time dependence of nighttime thermospheric neutral winds over Millstone Hill. J. Geophys. Res.: Space Phsy., 107(A5), SIA 3-1-SIA 3-9. https://doi.org/10.1029/2001JA000300

Fejer, B. G., Jensen, J. W., and Su, S. Y. (2008). Seasonal and longitudinal dependence of equatorial disturbance vertical plasma drifts. Geophys. Res. Lett., 35(20), L20106. https://doi.org/10.1029/2008GL035584

Fukao, S., Ozawa, Y., Yamamoto, M., and Tsunoda, R. T. (2003). Altitudeextended equatorial spread $F$ observed near sunrise terminator over 
Indonesia. Geophys. Res. Lett., 30(22), 2137.

https://doi.org/10.1029/2003GL018383

Gonzalez, W. D., Joselyn, J. A., Kamide, Y., Kroehl, H. W., Rostoker, G., Tsurutani, B. T., and Vasyliunas, V. M. (1994). What is a geomagnetic storm?. J. Geophys. Res.: Space Phys., 99(A4), 5771-5792. https://doi.org/10.1029/93JA02867

Haerendel, G., Eccles, J. V., and Çakir, S. (1992). Theory for modeling the equatorial evening ionosphere and the origin of the shear in the horizontal plasma flow. J. Geophys. Res.: Space Phys., 97(A2), 1209-1223. https://doi.org/10.1029/91JA02226

Huang, C. S., and Kelley, M. C. (1996). Nonlinear evolution of equatorial spread F: 2. Gravity wave seeding of Rayleigh-Taylor instability. J. Geophys. Res.: Space Phys., 101(A1), 293-302. https://doi.org/10.1029/95JA02210

Huang, C. S., de La Beaujardiere, O., Roddy, P. A., Hunton, D. E., Ballenthin, J. O., and Hairston, M. R. (2013). Long-lasting daytime equatorial plasma bubbles observed by the C/NOFS satellite. J. Geophys. Res.: Space Phys., 118(5), 2398-2408. https://doi.org/10.1002/jgra.50252

Huang, F. Q., Lei, J. H., and Dou, X. K. (2017). Daytime ionospheric longitudinal gradients seen in the observations from a regional BeiDou GEO receiver network. J. Geophys. Res.: Space Phys., 122(6), 6552-6561. https://doi.org/10.1002/2017JA023881

Huang, F. Q., Lei, J. H., Dou, X. K., Luan, X. L., and Zhong, J. H. (2018). Nighttime medium-scale traveling ionospheric disturbances from airglow imager and Global Navigation Satellite Systems observations. Geophys. Res. Lett., 45(1), 31-38. https://doi.org/10.1002/2017GL076408

Huang, F. Q., Otsuka, Y., Lei, J. H., Luan, X. L., Dou, X. K., and Li, G. Z. (2019). Daytime periodic wave-like structures in the ionosphere observed at low latitudes over the Asian-Australian sector using total electron content from Beidou geostationary satellites. J. Geophys. Res.: Space Phys., 124(3), 2312-2322. https://doi.org/10.1029/2018JA026443

Huang, F. Q., Lei, J. H., Otsuka, Y., Luan, X. L., Liu, Y., Zhong, J. H., and Dou, X. K. (2021). Characteristics of medium-scale traveling ionospheric disturbances and ionospheric irregularities at mid-latitudes revealed by the total electron content associated with the beidou geostationary satellite. IEEE Trans. Geosci. Remote Sens., 59(8), 6424-6430. https://doi.org/10.1109/TGRS.2020.3032741

Huba, J. D., Joyce, G., and Krall, J. (2008). Three-dimensional equatorial spread $F$ modeling. Geophys. Res. Lett., 35(10), L10102. https://doi.org/10.1029/2008GL033509

Hysell, D. L. (2000). An overview and synthesis of plasma irregularities in equatorial spread F. J. Atmos. Sol.-Terr. Phys., 62(12), 1037-1056. https://doi.org/10.1016/S1364-6826(00)00095-X

Jiang, C. H., Yang, G. B., Liu, J., Yokoyama, T., Komolmis, T., Song, H., Lan, T., Zhou, C., Zhang, Y. N., and Zhao, Z. Y. (2016). lonosonde observations of daytime spread $F$ at low latitudes. J. Geophys. Res.: Space Phys., 121(12), 12093-12103. https://doi.org/10.1002/2016JA023123

Kelley, M. C. (2009). The Earth's lonosphere: Plasma Physics and Electrodynamics (2nd ed). San Diego, CA: Academic Press.

Krall, J., Huba, J. D., and Fritts, D. C. (2013). On the seeding of equatorial spread F by gravity waves. Geophys. Res. Lett., 40(4), 661-664. https://doi.org/10.1002/grl.50144

Lei, J. H., Wang, W. B., Burns, A. G., Solomon, S. C., Richmond, A. D., Wiltberger, M., Goncharenko, L. P., Coster, A., and Reinisch, B. W. (2008). Observations and simulations of the ionospheric and thermospheric response to the December 2006 geomagnetic storm: Initial phase. J. Geophys. Res.: Space Phys., 113(A1), A01314. https://doi.org/10.1029/2007JA012807

Lei, J. H., Huang, F. Q., Chen, X. T., Zhong, J. H., Ren, D. X., Wang, W. B., et al. (2018). Was magnetic storm the only driver of the long-duration enhancements of daytime total electron content in the Asian-Australian sector between 7 and 12 September 2017?. J. Geophys. Res.: Space Phys., 123, 3217-3232. https://doi.org/10.1029/2017JA025166

Li, G. Z., Ning, B. Q., Hu, L. H., Liu, L. B., Yue, X. N., Wan, W. X., Zhao, B. Q., Igarashi, K., Kubota, M., ... Liu, J. Y. (2010). Longitudinal development of low latitude ionospheric irregularities during the geomagnetic storms of July
2004. J. Geophys. Res.: Space Phys., 115(A4), A04304.

https://doi.org/10.1029/2009JA014830

Li, G. Z., Otsuka, Y., Ning, B. Q., Abdu, M. A., Yamamoto, M., Wan, W. X., Liu, L. B., and Abadi, P. (2016). Enhanced ionospheric plasma bubble generation in more active ITCZ. Geophys. Res. Lett., 43(6), 2389-2395.

https://doi.org/10.1002/2016GL068145

Li, G. Z., Ning, B. Q., Wang, C., Abdu, M. A., Otsuka, Y., Yamamoto, M., Wu, J., and Chen, J. S. (2018). Storm-enhanced development of postsunset equatorial plasma bubbles around the meridian $120^{\circ} \mathrm{E} / 60^{\circ} \mathrm{W}$ on 7-8 September 2017. J. Geophys. Res.: Space Phys., 123(9), 7985-7998.

https://doi.org/10.1029/2018JA025871

Lin, C. H., Richmond, A. D., Heelis, R. A., Bailey, G. J., Lu, G., Liu, J. Y., Yeh, H. C., and Su, S. Y. (2005). Theoretical study of the low- and midlatitude ionospheric electron density enhancement during the October 2003 superstorm: Relative importance of the neutral wind and the electric field. $J$. Geophys. Res.: Space Phys., 110(A12), A12312. https://doi.org/10.1029/2005JA011304

Luo, W. H., Xiong, C., Xu, J. S., Zhu, Z., and Chang, S. S. (2020). The low-latitude plasma irregularities after sunrise from multiple observations in both hemispheres during the recovery phase of a storm. Remote Sens., 12(18), 2897. https://doi.org/10.3390/rs12182897

Ma, G. Y., and Maruyama, T. (2006). A super bubble detected by dense GPS network at east Asian longitudes. Geophys. Res. Lett., 33(21), L21103. https://doi.org/10.1029/2006GL027512

Makela, J. J., and Otsuka, Y. (2012). Overview of nighttime ionospheric instabilities at low- and mid-latitudes: coupling aspects resulting in structuring at the mesoscale. Space Sci. Rev., 168(1), 419-440. https://doi.org/10.1007/s11214-011-9816-6

Nayak C., Tsai, L. C., Su, S. Y., Galkin, I. A., Caton, R. G., and Groves, K. M. (2017). Suppression of ionospheric scintillation during St. Patrick's Day geomagnetic super storm as observed over the anomaly crest region station Pingtung, Taiwan: A case study. Adv. Space Res., 60(2), 396-405. https://doi.org/10.1016/j.asr.2016.11.036

Nishioka, M., Saito, A., and Tsugawa, T. (2008). Occurrence characteristics of plasma bubble derived from global ground-based GPS receiver networks. J. Geophys. Res.: Space Phys., 113(A5), A05301. https://doi.org/10.1029/2007JA012605

Otsuka, Y., Shiokawa, K., Ogawa, T., and Wilkinson, P. (2002). Geomagnetic conjugate observations of equatorial airglow depletions. Geophys. Res. Lett., 29(15), 43-1-43-4. https://doi.org/10.1029/2002GL015347

Pi, X., Mannucci, A. J., Lindqwister, U. J., and Ho, C. M. (1997). Monitoring of global ionospheric irregularities using the worldwide GPS network. Geophys. Res. Lett., 24(18), 2283-2286. https://doi.org/10.1029/97GL02273

Richmond, A. D., and Lu, G. (2000). Upper-atmospheric effects of magnetic storms: A brief tutorial. J. Atmos. Sol.-Terr. Phys., 62(12), 1115-1127. https://doi.org/10.1016/S1364-6826(00)00094-8

Sripathi, S., Abdu, M. A., Patra, A. K., and Ghodpage, R. N. (2018). Unusual generation of localized EPB in the dawn sector triggered by a moderate geomagnetic storm. J. Geophys. Res.: Space Phys., 123(11), 9697-9710. https://doi.org/10.1029/2018JA025642

Tulasi Ram, S., Rama Rao, P. V. S., Prasad, D. S. V. V. D., Niranjan, K., Gopi Krishna, S., Sridharan, R., and Ravindran, S. (2008). Local time dependent response of postsunset ESF during geomagnetic storms. J. Geophys. Res.: Space Phys., 113(A7), A07310. https://doi.org/10.1029/2007JA012922

Tulasi Ram, S., Ajith, K. K., Yamamoto, M., Otsuka, Y., Yokoyama, T., Niranjan, K., and Gurubaran, S. (2015). Fresh and evolutionary-type field-aligned irregularities generated near sunrise terminator due to overshielding electric fields. J. Geophys. Res.: Space Phys., 120(7), 5922-5930. https://doi.org/10.1002/2015JA021427

Wan, X., Xiong, C., Wang, H., Zhang, K. D., Zheng, Z. C., He, Y., and Yu, L. (2019). A statistical study on the climatology of the Equatorial Plasma Depletions occurrence at topside ionosphere during geomagnetic disturbed periods. J. Geophys. Res.: Space Phys., 124(10), 8023-8038. 
https://doi.org/10.1029/2019JA026926

Wu, K., Xu, J. Y., Yue, X. N., Xiong, C., Wang, W. B., Yuan, W., Wang, C., Zhu, Y., and Luo, J. (2020). Equatorial plasma bubbles developing around sunrise observed by an all-sky imager and global navigation satellite system network during storm time. Ann. Geophys., 38(1), 163-177. https://doi.org/10.5194/angeo-38-163-2020

Xiong, C., Lühr, H., and Fejer, B. G. (2015). Global features of the disturbance winds during storm time deduced from CHAMP observations. J. Geophys. Res.: Space Phys., 120(6), 5137-5150. https://doi.org/10.1002/2015JA021302 Xiong, C., Stolle, C., and Lühr, H. (2016). The Swarm satellite loss of GPS signal and its relation to ionospheric plasma irregularities. Space Wea., 14(8), 563-577. https://doi.org/10.1002/2016SW001439

Yokoyama, T., Shinagawa, H., and Jin, H. (2014). Nonlinear growth, bifurcation, and pinching of equatorial plasma bubble simulated by three-dimensional high-resolution bubble model. J. Geophys. Res.: Space Phys., 119(12), 10474-10482. https://doi.org/10.1002/2014JA020708

Zalesak, S. T., and Ossakow, S. L. (1980). Nonlinear equatorial spread F: Spatially large bubbles resulting from large horizontal scale initial perturbations. J. Geophys. Res.: Space Phys., 85(A5), 2131-2142. https://doi.org/10.1029/JA085iA05p02131 